\title{
LUXURY BRANDING IN EMERGING MARKETS
}

\author{
Beate Stiehler, University of Johannesburg, South Africa, bstiehler@uj.ac.za \\ Linda W. Lee, KTH Royal Institute of Technology, Sweden, llee@kth.se
}

\begin{abstract}
In March 2012, Gap entered the South African market, but with a different pricing strategy to the one followed in the USA. While the brand is known as an affordable clothing brand in the USA, its goods were priced substantially higher in South Africa than in the USA. The same Gap Tshirt sold for \$16 in the USA was being sold at \$40 in South Africa. The positioning of the Gap brand as a luxury brand in the South African market suggests that what constitutes a luxury brand is not the same across global markets. This paper explores whether this mode of market entry is a sustainable business model or if the mode of entry is only viable for short-term success. In pursuing this line of thinking, the concept of the opportunistic luxury brand is presented. An opportunistic luxury brand is defined as a brand that is not normally known as a luxury brand in other markets (i.e. other countries) and is adopting a luxury brand positioning in a particular market. This paper develops and offers a research agenda for luxury brands in emerging markets.

References available upon request.
\end{abstract}




\section{LUXURY BRANDING IN EMERGING MARKETS}

In March 2012, Gap entered the South African market, but with a different pricing strategy to the one followed in the USA. While the brand is known as an affordable clothing brand in the USA, its goods were priced substantially higher in South Africa than in the USA. The same Gap Tshirt sold for \$16 in the USA was being sold at \$40 in South Africa. The purpose of the proposed research is to explore whether this mode of market entry is a sustainable business model or if the mode of entry is only viable for short-term success. This paper develops and offers a research agenda for luxury brands in emerging markets.

\section{Introduction}

In March 2012, Gap entered the South African market, but with a different pricing strategy to the one followed in the USA. While the brand is known as an affordable clothing brand in the USA, its goods were priced substantially higher in South Africa than in the USA. The same Gap Tshirt sold for \$16 in the USA was being sold at \$40 in South Africa. Some of the reasons provided by Gap for such a pricing strategy included higher shipping costs, import duties, and because Gap believes the American brand image is associated with high quality. The former president of Gap in Asia (where a similar strategy was followed) said "When you go to a country like Israel or Australia or Athens or Turkey, these customers look at it as 'this is an American icon that is finally finally coming to my country, and now that they're going to teach me what casual apparel is all about.' And they're just euphoric over it." (Wong, 2012).

This quotation illustrates how the Gap brand is interpreting the market potential in emerging economies. However, while this high-price, high-quality strategy suggests a luxury positioning, the literature on luxury brands, product positioning, and the development of emerging markets, suggests that a strategy like the one pursued by Gap may not be a sustainable one. South African consumers are connected to the information highway and are also travelling more frequently than in the past (Statistics South Africa, 2012).These consumers will eventually discover that Gap's position in South Africa, is that of an opportunistic luxury brand versus that of a true luxury brand (like Gucci or Louis Vuitton). The question therefore is, how will this information affect the consumers' perception of this opportunistic luxury brand, as well as other brands pursuing a similar strategy, and what are the overall business implications?

The purpose of the proposed research is to explore whether this mode of market entry is a sustainable business model or if the mode of entry is only viable for short-term success. In pursuing this line of thinking, we introduce the concept of the opportunistic luxury brand. An opportunistic luxury brand is defined as a brand that is not normally known as a luxury brand in other markets (i.e. other countries) and is adopting a luxury brand positioning in a particular market. This paper develops and offers a research agenda for luxury brands in emerging markets.

\section{Luxury Brands}

When consumers think of true luxury brands, the list tends to be similar worldwide and includes brand names such as Louis Vuitton, Hermes, Prada, Gucci, and Fendi (Millward Brown, 2013). However, many of these luxury brands offer logo-typed accessories or second lines at a lower 
price than the true luxury brands (but still much higher priced than a similar product of the same quality). Produced on a larger scale, the usual rarity and scarcity found in the typical luxury brands has led to these second line offerings to be described as luxury fashion brands (Kapferer, 2012). Luxury fashion brands are described as having qualitative rarity, with high price being a key attribute, and a goal of building pricing power such that consumers become price-insensitive (Kapferer, 2012). In the Gap example, this opportunistic luxury brand is attempting to pursue qualitative rarity with a high price strategy.

\section{Positioning}

The positioning of a product is a deliberate decision made by a marketer to try to achieve a defined brand image relative to its competition in the market (Hawkins \& Mothersbaugh, 2012). The effective positioning of a product is critical in the creation of a competitive advantage for the firm or brand (Lamb, Hair, McDaniel, Boshoff, Terblanche, Elliot, and Klopper, 2010).

Differentiation can be defined as "... the process of identifying something that is different about a firm or its products" (Lamb et al. 2010:204). It is argued that differentiation and competitive advantage essentially means the same thing, because being different is what will give a firm its competitive advantage over the competition. A firm or brand can aim to be different in terms of its price, quality, product attributes or image. Whichever of these identified differentiation variables are chosen, it is suggested that the variables should meet the following four criteria before it can be accepted as a differentiating factor. The criteria include (1) sustainability over the long term, (2) being desirable by customers, (3) being marketed at a price consumers are willing to pay, and (4) must be profitable (Lamb et al., 2010).

\section{Conspicuous Consumption}

Berthon, Pitt and Parent(2009) identify three dimensions of luxury brands: functional (e.g. product quality), experiential (e.g. of personal hedonic nature), and symbolic (e.g. conspicuous to others and enhances the consumer's concept of self). The symbolic dimension can be described as conspicuous consumption and Zhan and He (2012) found that conspicuous consumption is a key reason for purchasing luxury brands in China. Examples include purchasing a Louis Vuitton handbag or a Rolex watch, not because of personal taste or luxury, but because of a desire to fit within particular social groups.

Similarly in South Africa, research indicates that consumers are spending on luxury alcohol brands because they symbolise prosperity. Pricey brands like Johnnie Walker have become a familiar sight in informal taverns in the townships of South Africa, where drinkers are often seen mixing these expensive spirits with soft drinks like Fanta. The brand manager for Johnnie Walker said "a lot of our spirits' consumption is driven by status and aspiration" and "the emerging consumer, when he wants to show off, he will buy spirits... and when there's a challenge with his income he'll return to beer" (Wong, 2012:1).

Veblen's (1899) contention that people use the conspicuous consumption of luxury goods to convey wealth, power, and status therefore seems to be likely to be more pronounced in emerging markets. As such, this conspicuous consumption of luxury or the symbolic dimension 
of luxury brands appears to be more important than the functional or experiential dimensions in emerging economies.

\section{Emerging Markets}

Emerging markets can be defined as "... those countries that have growing economies and a growing middle class. Some of these countries were once poor, and some still have high rates of poverty. Many are undergoing profound social and political change for the future" (Logue, 2011:1). The BRICS countries are a group of leading emerging economies consisting of Brazil, Russia, India, China and South Africa. This paper considers South Africa specifically, as there are differences among each country in the emerging markets (Hoskisson, Eden, Lau, and Wright, 2000).

A major change that has occurred in post-apartheid South Africa is the emergence of a very strong middle class. With R237 billion in purchasing power at the beginning of 2012, it is projected that this segment will be responsible for the most growth in the South African economy (Digital Fire, 2012). It is recognised that there are opportunities in niche areas such as cosmetics and clothing and some international brands have already started to enter this market: The Body Shop, Mango (Euromonitor International, 2012) and Louis Vuitton handbags (Reuters, 2013) to name a few.

Cui and Lui (2001) argue that as multinational corporations enter emerging markets, category sales growth could be high at first, because these brands are starting from a low base and because of the high rate of growth of high income groups, rather than overall population growth. They contend that the initial high rates of growth may not be sustainable over the long term and point out that brand switching is prevalent. While Cui and Lui (2001) were studying multinational corporations in general and not luxury brands in particular, their study likely has implications for luxury brands.

\section{Research Agenda and Propositions}

The positioning of the Gap brand as a luxury brand in the South African market suggests that what constitutes a luxury brand is not the same across global markets. Furthermore, a luxury brand-buying culture that is driven by conspicuous consumption is an important consideration to be taken into account for those brands targeting the middle class in emerging markets (which is currently the fastest growing segment in this country). The literature on positioning strategies indicates that the differentiating factors used to position a brand should be sustainable.

Opportunistic luxury brands (like Gap in South Africa) are using high price, the key attribute of qualitative rarity, as part of their positioning strategy in emerging markets. However, emerging markets are not isolated from the rest of the world and consumers could become aware of the original positioning of these brands in their countries of origin.

These concerns raise the following general research questions:

1. Is a high-price strategy a sustainable differentiating factor to use to position opportunistic luxury brands in this market? 
2. How long will an opportunistic luxury brand strategy be able to achieve a desirable position in the mind of the emerging market consumer?

3. Might opportunistic luxury brands be forced to adjust their strategies in future as soon as true luxury brands, the stronger competitors, enter the market?

4. In instances where opportunistic luxury brands are entering emerging markets and pricing themselves at a much higher price differential to average products in the same category, where does a true luxury brand see competitive advantage in the same emerging market?

Based on Hoskisson et al. (2000), one might expect that, following institutional theory, a price differential could be possible for a short period of time. However, with global information and savvy consumers, such a price differential would not be sustainable over time. An opportunistic luxury brand would be expected to become less desirable when consumers realize that the positioning in the emerging market is different than in the brand's country of origin. With the Gap example, a true luxury brand such as Gucci or Prada could either enter the same emerging market as Gap by:

a) maintaining a similar price differential as in developed countries (i.e. at a much higher price in emerging markets than in developed countries to maintain the price differential) or

b) with similar prices as Gucci or Prada in developed countries (and a much narrower price differential versus Gap).

If a true luxury brand undertakes (a), the luxury brand might achieve high prices but low volume. If it undertakes (b), the luxury brand might achieve similar prices as it does in other countries and achieve higher volume.

Drawing on institutional theory, more specifically its normative pillar, this paper further contends that the cultural differences between developed countries and emerging markets require differences in how luxury brands enter new markets. In the early stages of market entry, Hoskisson et al. (2000) utilize institutional theory to explain business strategies initially. Postentry, transaction cost economics and the resource-based view become more important. It is therefore argued that, after a certain period, a high price position (as is the case with Gap's current strategy in South Africa) will no longer be accepted by the emerging market consumer. These consumers in emerging markets will develop greater knowledge of global brands and realize when a brand has an inconsistent position in the emerging market compared to other markets. As this brand knowledge grows, there may be a need for such a brand to offer greater value at a lower price as suggested by Cui and Lui (2001) and therefore transaction cost economics and resource-based view might become more important (Hoskisson et al., 2000).

Based on the literature and the Gap example, the following propositions are put forward:

Proposition One: The construct of a luxury brand is not global, as the position a brand holds in the mind of a consumer in a developed country will be different to the one in an emerging market.

Proposition Two: Culture of countries, characterized as conspicuous consumption, plays a moderating influence on market strategies for luxury brands. 
Proposition Three: While conspicuous consumption may be a motivator for opportunistic luxury brands in the short term, this may not be enough over the longer term because value then becomes more important than conspicuous consumption.

Proposition Four: An opportunistic luxury brand can utilize a high price strategy in emerging markets only for a limited time, as consumer knowledge moderates that brand's intended positioning (through high price) to achieve the consumer's brand perception.

Proposition Five: A true luxury brand will have advantages compared to an opportunistic luxury brand in the same category when entering an emerging market where the opportunistic luxury brand has already entered.

\section{Conclusion}

This paper identifies a phenomenon that has been under researched in international business: that of traditionally affordable brands positioning themselves as luxury brands in emerging markets. It also identifies research questions and propositions that warrant future attention by marketing and international business researchers. It is hoped that this paper provides a platform from which researchers can undertake new investigations.

\section{References}

Berthon, P., Pitt, L., Parent, M., \& Berthon, J. P. (2009). Aesthetics and Ephemerality. California Management Review, 52(1), 45-66.

Cui, G., \& Liu, Q. (2001). Emerging market segments in a transitional economy: a study of urban consumers in China. Journal of International Marketing, 9(1), 84-106.

Digital Fire. (2012). Understanding the black diamond market. Retrieved April 4, 2012 from http://www.digitalfire.co.za/blog/understanding-the-black-diamond-market/

Euromonitor International, (2012). Retailing in South Africa. Euromonitor International.

Hawkins, D.I. Mothersbaugh, D.L. (2013). Consumer behaviour: Building marketing strategy. $12^{\text {th }}$ ed. New York: McGraw-Hill/Irwin.

Hoskisson, R. E., Eden, L., Lau, C. M., \& Wright, M. (2000). Strategy in emerging economies. Academy of management journal, 43(3), 249-267.

Kapferer, J. N. (2012). Abundant rarity: The key to luxury growth. Business Horizons, 55(5), 453-462.

Lamb, C., Hair, J., McDaniel, C., Boshoff, C., Terblanche, N., Elliot, R., Klopper, H.B. (2010). Marketing. $4^{\text {th }}$ ed. South Africa: Oxford University Press. South Africa.

Logue, A.C. (2011). Defining emerging markets. Retrieved, May 30, 2013 from:http:// www.dummies.com/how-to/content/defining-emerging-markets.html

Millward Brown. (2013). Top 10 Luxury Brands of 2013. Retrieved 20 September, 2013 from: http://luxpresso.com/photogallery-style/top-10-luxury-brands-of-2013/23356

Reuters. (2013). Africa's thirst draws in luxury brands. Retrieved September 16, 2013 from: http://www.fin24.com/Economy/Africas-thirst-draws-in-luxury-brands-20130614

Statistics South Africa. 2012. Tourism 2012. Retrieved 20 September, 2013 from: http://www.statssa.gov.za/publications/Report-03-51-02/Report-03-51-022012.pdf 
Veblen (1899), op. cit.; P. Bourdieu, Distinction: A Social Critique of the Judgment of Taste Cambridge, MA: Harvard University Press 1984.

Wong, S. (2012). Gap enters South Africa: Will shoppers follow? Retrieved 18 September, 2013 from: http://www.minyanville.com/sectors/consumer/articles/thegapgpswmtanfgap /3/30/2012/id/40168?refresh=1

Zhan, L., \& He, Y. (2012). Understanding luxury consumption in China: Consumer perceptions of best-known brands. Journal of Business Research, 65(10), 1452-1460. 